\title{
Improving Aerodynamic Efficiency and Decreasing Drag Coefficient of an F1 in Schools Race Car
}

\author{
Ao $\mathrm{Gai}^{1}$ \\ ${ }^{1}$ Deerfield Academy, Massachusetts, United States \\ Correspondence: Ao Gai, Deerfield Academy, 7 Boyden Lane, Deerfield, MA 01342, United States.
}

Received: February 6, 2021

Accepted: March 23, 2021

Online Published: March 29, 2021

doi:10.5539/mas.v15n2p73

URL: https://doi.org/10.5539/mas.v15n2p73

\begin{abstract}
To improve the aerodynamic efficiency of a Formula One (F1) in Schools race car, the original model of the car is evaluated and compared with a new design. The ideas behind the new design are supported by research about aerodynamics. Different potential designs are created with CAD software Fusion 360 and evaluated within CFD software Solid Edge 2020 with FloEFD. Empirical data shows how specific changes to the structure of race cars can improve aerodynamic efficiency by decreasing their aerodynamic drag. The experimental data and methods of this study can provide help and guidance for teenagers participating in the F1 in Schools competition program to solve the aerodynamic performance problems of racing cars and thereby increase youth interest in STEM programs, as well as their opportunities to learn about engineering and enter engineering careers.
\end{abstract}

Keywords: aerodynamics, computational fluid dynamics, drag coefficient, F1 in Schools

\section{Introduction}

\subsection{Background for the Research}

Formula One (F1) is one of the oldest, most popular, and most technologically advanced car racing championships in the world. From each team's attention to detail, such as the material used or the slightest tweak of designs, to the engineers' constant efforts to improve the aerodynamic efficiency and success of their race cars, $\mathrm{F} 1$ is a paradigm for the world's advancements in the automobile industry.

The challenge of designing and honing a race car to its maximum potential is brought to high school students by the F1 in Schools competition. F1 in Schools is a STEM challenge organized by Formula One to encourage high school students around the world to design a small version of an F1 car. The challenge requires the members of the participating teams to work together and create a race car that is fast and aerodynamically efficient.

This study is concerned with the improvement of an F1 in Schools race car, the same goal as real-life F1 teams have pursued throughout the sport's history. Finding the optimized angle and structure of the car's wing, the most efficient body shape of the car, and an aerodynamic rear wing are the three most important areas of improvement for this project.

\subsection{Research Trends}

An essential aspect of Formula One's technology is its advancements in aerodynamic innovations and designs. In 1968, Graham Hill appeared at the Monaco Grand Prix with a modest wing fitted on his Lotus 49B race car. This is widely considered the start of aerodynamic enhancement and improvement in F1 racing (Jennie, 2014). From that point on, aerodynamics - specifically, the creation of more negative lift, or downforce, with the balance of drag - has always been an aspect that F1 teams have focused on and, as such, has prompted increasingly complex and interesting wing designs on F1 cars.

During the ground effect era of F1 in the late 1970s and early 1980s, different teams across the F1 grid began exploring and taking advantage of this aerodynamic principle to decrease the drag and increase the downforce and cornering speed of their race cars (Graham, 2019). This is just one instance of how F1 teams have always attempted to design the fastest running machines on the grid with various aerodynamic innovations and improvements. In 2020, researchers Ilya Tolchinsky, Travis Carrigan and Joshua Dawson used CAD to optimize the front wing of a racing car and concluded that a higher angle of attack at the tip of the wing produces superior aerodynamic performance (Tolchinsky, Carrigan, \& Dawson, 2020). The work of researchers Jurij Iljaž, Leopold Škerget, Mitja Štrakl and Jure Marn in 2016 showed that the tail of a car has an important relationship with 
maintaining the downforce of a car, and the downforce increases with the height of the wing and reaches its maximum value at an $8^{\circ}$ angle of attack (Iljaž et al., 2016). John Shew and Leah Wyman completed the calculation and analysis of the front wing with FLUENT under three different conditions: wing out of ground effect, wing in ground effect, and wing with endplates in ground effect. The results showed that the FLUENT case for the wing with endplates in ground effect achieved an $80 \%$ increase in lift while increasing its L/D from 6.9 to 9.0 from the case of the wing out of ground effect and without endplates (John \& Leah, 2005). Ground effects have an impact on the design of the front wing of a car, but measures can be taken to reduce the impact.

Similar to the efforts of F1 teams and designers, this study focuses on the aerodynamic improvements of an F1 in Schools car, based on past research and aerodynamic principles.

\subsection{Purpose and Significance of the Research}

For this research project, an F1 in Schools race car had already been designed by the team, Boyden Challenger, which participated in the $2020 \mathrm{~F} 1$ in Schools challenge in China. The focus of the study is to improve the aerodynamic efficiency of the race car and ultimately to reduce its drag coefficient as much as possible. The focus on the drag coefficient is due to its normalization of the different factors of the car and environment, such as air density, speed, and car size, making direct comparisons of drag possible over a wide range of conditions. The efforts to alter the structure and design of the car are based on additional research into aerodynamics and how its efficiency can be improved. The experimental data and methods of this study can provide help and guidance for teenagers participating in the F1 in Schools competition program to solve the aerodynamic performance problems of racing cars and thereby encourage more young people to participate in the program and develop their interests in STEM.

\section{Methods and Theories}

\subsection{Methods}

Literature Research: One of the most important aspects of this study is its research concerning the basic principles of aerodynamics as well as potential areas of exploitation of these principles. While browsing different articles and papers online, useful knowledge, principles, and suggestions were categorically recorded and archived. The information collected served as the foundation for the altering of the structural and aerodynamic design of the original race car.

Computational Fluid Dynamics (CFD): The Solid Edge 2020 CFD computer software with FloEFD was used to digitally analyze the aerodynamic efficiency of the race car. New structural alterations of the race car can be put into the CFD software for virtual calculation, and the results of the tests can be evaluated. To ensure that a design exhibits aerodynamic improvement and a lowering of the drag coefficient, the CFD evaluations are all strictly controlled. Each of the different variables within the CFD software is set to a standard for all tests so that the difference between the evaluations more precisely reflects the effectiveness of different structural alterations, avoiding the potential for human or computational errors. The reason to use CFD is due to a lack of access to a wind tunnel, where the actual conditions can be measured and a more realistic drag on the car can be derived. Although the CFD model may not produce the most accurate evaluation compared to that of wind tunnels, it is the most accessible option that can acquire the needed information.

\subsection{Theories}

Lift: Lift is an upward force opposite to weight. For an object or a vehicle to elevate, the force of lift must be greater than that of its weight. For example, a helicopter's wings propel fast enough to generate lift that overcomes the weight of the aircraft itself, leading to takeoff (Brian, 2015) (see Figure 1).

Drag: Drag is the force that acts to slow an object down within fluids or air. In a sense, this idea is similar to friction generated by contact between different objects. Moving through water is harder than moving through air because water normally generates more drag than air.

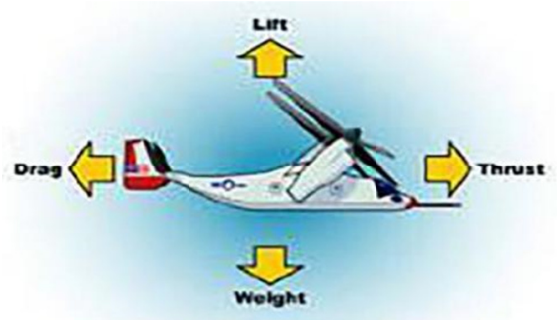

Figure 1. Force analysis of aircraft in air (Brian, 2015) 
Negative Lift: Negative lift, more commonly known as downforce, is the vertical force of lift in the opposite direction. Downforce is an essential consideration for road vehicles and race cars. The generation of downforce on race cars through their intended structural designs helps the cars achieve more stability and speed when going around corners. However, the more a car can generate downforce, the more the car can generate drag. Therefore, the compromise between these two aerodynamics components is of great consideration to many vehicle designers (Bryan, 2001).

Bernoulli's Equation and Principle: Bernoulli's Equation and its derived principle are named after Swiss mathematician and physician Daniel Bernoulli. The equation is presented below:

$$
\frac{1}{2} \rho v_{1}^{2}+\rho g h_{1}+P_{1}=\frac{1}{2} \rho v_{2}^{2}+\rho g h_{2}+P_{2}
$$

v: velocity, $\rho$ : fluid density, h: height, g: gravitational force, P: pressure

This equation indicates the conservation of the sum of kinetic, potential, and thermal energy, showing the relationship between velocity, pressure, and elevation. When Bernoulli's principle is applied to the wing of an aircraft or a vehicle, it suggests that when the velocity of air is greater on one side of the wing than the other, the pressure must be lower on that side than the other, since the variables are inversely proportional according to the equation. However, the gravitational force does not play a part when the principle is applied in aerodynamics, since buoyancy effects are not important. At the same time, Bernoulli's principle only applies to flow that is steady and without dissipation. With the appropriate design of wings, such a difference of pressure can serve as the generation of lift on an aircraft and downforce on vehicles (James, King \& W. Carlson, 2020) (see Figure 2).

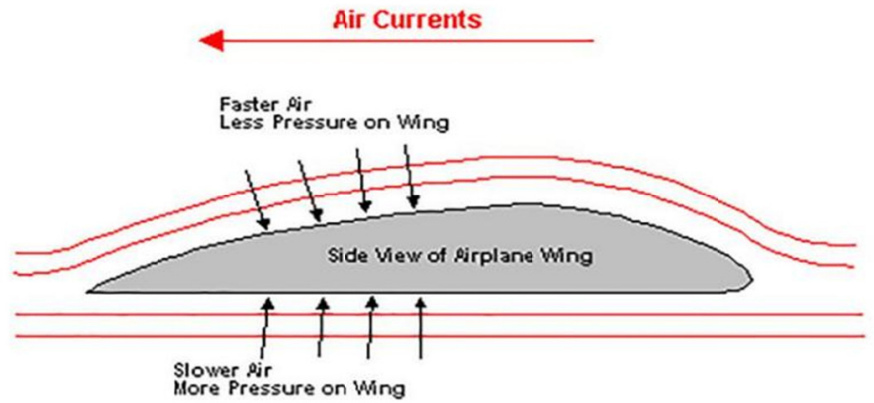

Figure 2. Bernoulli's principle airflow trajectory (The Columbia Electronic Encyclopedia)

Drag Coefficient: The drag coefficient is a numerical quantity calculated by a particular equation to represent the drag exerted on an object in a fluid environment. The drag coefficient is usually referred to as $\mathrm{Cd}$, and the equation is the following:

$$
C d=\frac{D}{0.5 \rho A v^{2}}
$$

D: drag, A: the reference area of the object

The reference area is an important yet arbitrary factor when calculating the drag coefficient. The frontal and planform area of vehicles are usually used as the reference area for the equation. Selecting the appropriate reference area and clearly identifying it is key for the equation to produce an unambiguous drag coefficient (Nancy, 2015). The drag coefficient, although dimensionless, is a derived number which is directly associated with the aerodynamic efficiency of a vehicle. Since it normalizes factors such as fluid idensity, reference area, and velocity in individual vehicles, the drag coefficient can produce a direct and universal comparison of the drag between different vehicles.

Ground Effect: The ground effect, different from that of aircraft wings, is an aerodynamic term used to describe the creation of fast-flowing and low-pressure air flow beneath a car in order to reduce drag and create downforce. A massive amount of downforce can be generated through the creation of a ground effect with a minimum amount of drag creation, which is why the idea of the ground effect has been adopted by race car designers since its implementation in the late 1970s (Seas). 


\section{Race Car Design, Analysis, and Results}

\subsection{Software}

A crucial part of the project is the computer software that allows alterations to be made to the design of the original race car and completes the analysis of the aerodynamics. Here Autodesk Fusion 360 is used, as well as FloEFD and Solid Edge 2020.

Autodesk Fusion 360 is a computational-aided design (CAD) software developed by Autodesk. It is an easily understandable and usable software that allows 3D models to be created, shaped, and exported. This CAD software is the basis of operation for the original structural design of the Boyden Challenger, the F1 in Schools model race car that this study focuses on.

Solid Edge 2020, with the implementation of FloEFD, can perform CFD analysis on the design of the race car that is exported from Fusion 360. FloEFD vitally allows the exported race car model to be simulated within a correct environment with the correct data restrictions. Furthermore, FloEFD records the essential data and 3D flow behaviors observed from different perspectives.

\subsection{Analytical Restrictions}

To ensure the validity of the results of any structural design change, there are several important analytical restrictions that are made constant for every flow analysis. Each analysis is run on one device with the same hardware and settings. With a constant environment for the different designs, the difference in results can be accurately evaluated. The constants and restrictions are below.

Table 1. Hardware configuration

\begin{tabular}{llllll}
\hline Processor & Internal Storage & System Version & CAD Software & CFD Software & CPU Speed \\
\hline Intel(R) & $8041 \mathrm{MB} /$ & Windows 10 & Autodesk & FloEFD & $2592 \mathrm{MHz}$ \\
Core(TM) & $134217727 \mathrm{MB}$ & (Version & Fusion 360 & FES2019.1.0. & \\
i7-9750H CPU & & $10.0 .18363)$ & & Build: 4540 & \\
@ $2.60 \mathrm{GHZ}$ & & & & & \\
\hline
\end{tabular}

Table 2. Flow Analysis Conditions-1

\begin{tabular}{|c|c|c|c|c|c|c|}
\hline $\begin{array}{l}\text { Flow Analysis } \\
\text { Type }\end{array}$ & $\begin{array}{l}\text { Coordinate } \\
\text { System }\end{array}$ & $\begin{array}{l}\text { Reference } \\
\text { Axis }\end{array}$ & \multicolumn{3}{|l|}{ Volume } & Flow Type \\
\hline & & & $\mathrm{X}$-axis & $\mathrm{Y}$-axis & $\mathrm{Z}$-axis & \\
\hline $\begin{array}{l}\text { Object Exterior } \\
\text { (excluding any } \\
\text { inner space) }\end{array}$ & Default & $X$ & $\begin{array}{l}-0.4 \mathrm{~m} \sim \\
0.8 \mathrm{~m}\end{array}$ & $\begin{array}{l}-0.2 \mathrm{~m} \sim \\
0.2 \mathrm{~m}\end{array}$ & $\begin{array}{l}0 \mathrm{~m} \sim \\
0.25 \mathrm{~m}\end{array}$ & $\begin{array}{l}\text { Laminar and } \\
\text { Turbulent Flow }\end{array}$ \\
\hline
\end{tabular}

Table 3. Flow Analysis Conditions-2

\begin{tabular}{|c|c|c|c|c|c|c|}
\hline Fluid & Pressure & Temperature & Speed & & & Others \\
\hline \multirow{2}{*}{ Air } & \multirow{2}{*}{$101325.00 \mathrm{~Pa}$} & \multirow{2}{*}{$293.20 \mathrm{~K}$} & $\mathrm{X}$-axis & Y-axis & Z-axis & \multirow{2}{*}{ Disabled } \\
\hline & & & $25.000 \mathrm{~m} / \mathrm{s}$ & $0 \mathrm{~m} / \mathrm{s}$ & $0 \mathrm{~m} / \mathrm{s}$ & \\
\hline
\end{tabular}

Note. Others includes: Transient State Analysis, Object Heat Conduction, Rotation, Weight, High Mach Number Flow, Humidity.

At the same time, FloEFD allows specific results to be derived from flow tests. Three essential data can be evaluated from every flow test: drag force, lift, and the drag coefficient. While the drag force and lift can be directly derived from the flow model, the drag coefficient is derived from a manually inserted equation (see "Drag Coefficient" on pg.4):

$$
C d=\frac{D}{0.5 \rho A v^{2}}
$$




\subsection{First Model Analysis}

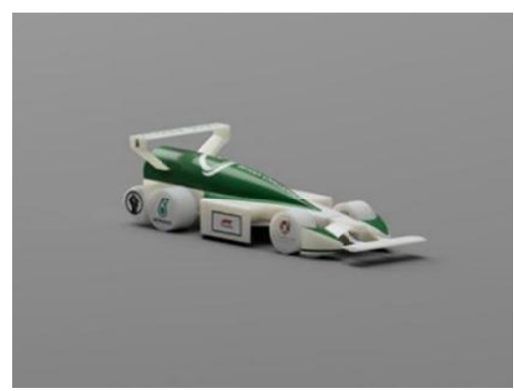

Figure 3. Rendered Original Boyden Challenger Race Car

The first model of the Boyden Challenger was designed for participation in the F1 in Schools competition in the summer of 2020. Staying within the regulations, the race car used the design of a double front wing, installing two covering bodyworks for the wheel behind the required main wing (see Figure 3). One bluff body in front of another would be effective in reducing the drag of the object in the downstream of the flow. This is the basic idea behind the design of the bodywork of the front wings. Without creating more drag for the middle part of the flow over the body, the two bluff bodies in front of the front wheels can effectively guide as much airflow as possible past the front wheels, ensuring as little drag as possible (Keith \& Anatol, 1984). With this design, the required main wing for the front wing can stay at a horizontal angle without an angle of attack, making it as aerodynamically efficient as possible. The main body shape is a traditional streamline design that is often seen on F1 in Schools race cars. The rear wing is designed to be installed on the main body of the car, protruding at a 90-degree angle from the bodywork to minimize interference drag. Two converging bodyworks are also designed behind the rear wheels. In addition, the rear of the car has a space in which a CO2 cartridge is inserted. The CO2 cartridge is the source of thrust for the car when it is pierced. However, all of the tested models of the car do not involve the insertion of the cartridge, since the main goal of the study is to make the car itself as aerodynamically efficient as possible.

Table 4. Flow analysis result of the first model

\begin{tabular}{ccc}
\hline Name & Unit & Value \\
\hline Drag & $\mathrm{N}$ & 0.426 \\
Lift & $\mathrm{N}$ & 0.020 \\
$\mathrm{Cd}$ & & 0.493 \\
\hline
\end{tabular}

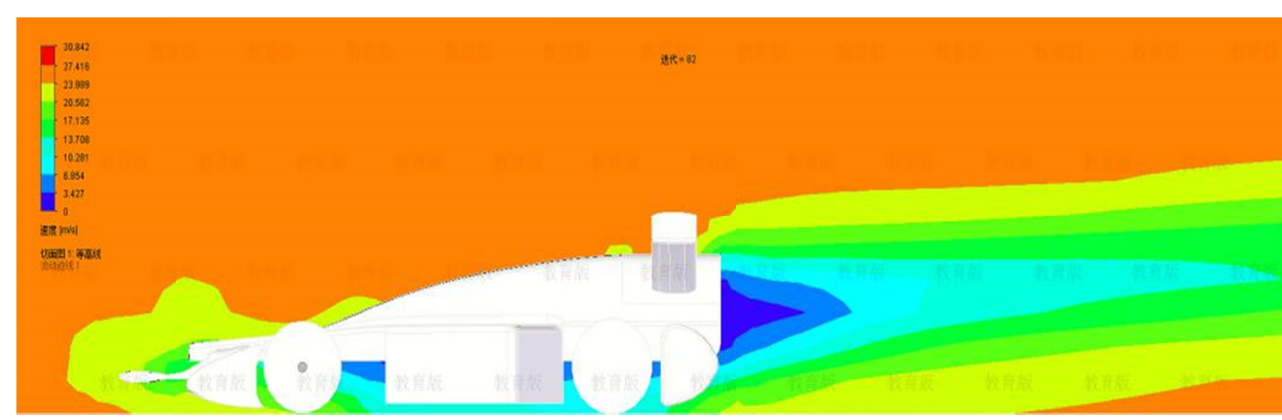

Figure 4. The side view of the airflow velocity

Combining the results with the observation of airflow around the car, there are several obvious paths for reducing the drag (see Figure 4). First, there is an apparent area of low-speed air around the front wing of the car, so the optimization of the front wing may be helpful for reducing the drag. Second, there is an area of low-speed air beneath the car, which indicates a separation of flow and the creation of a higher-pressure zone beneath the car. Finally, the most apparent issue is the large wake behind the car, an issue that is known to be a major cause 
of drag on vehicles. Fixing these issues observed in the first model of the car are the main goals for improving upon the drag coefficient of the car.

\subsection{Front Wing Changes}

Front wing alteration is the first consideration of structural change for the race car. An attempt is made to increase the angle of attack for the forebody of the front wheel, directing the airflow upwards rather than splitting the air from the middle (Sun, 2018). The air that would travel below the forebody of the wheel is observed to be entering the space between the bodywork and the wheel, creating a volume of separated flow and the associated drag with the wheel (see Figure 5). This effect is also reduced by raising the angle and lowering the nose of the forebody, since this causes more air to move upwards rather than downwards. The alteration of the shape of this structure also does not change the frontal reference area of the car, since the structure is directly in front of the front wheels, and the area is within the wheel.

Figures 5 and 6 and Tables 5 and 6 show the results from the front wing alterations:

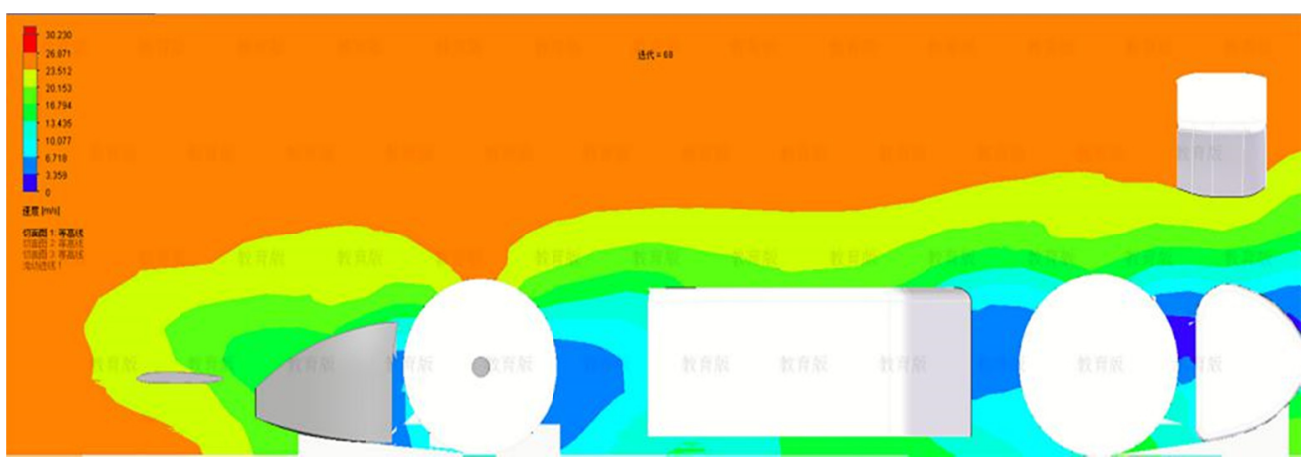

Figure 5. Front wing alteration 1 - flow velocity side view

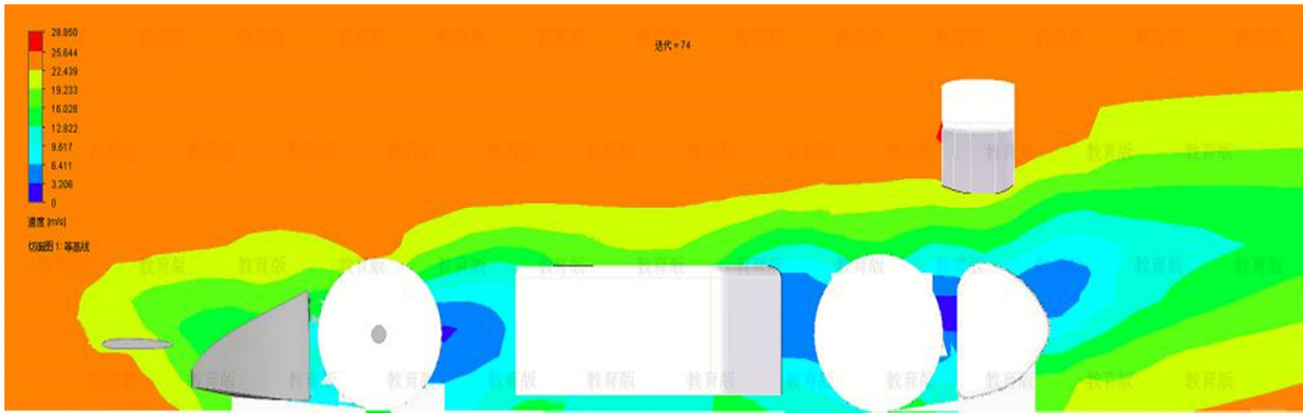

Figure 6. Front wing alteration 2 - flow velocity side view

Table 5. Front wing alteration 1 data

\begin{tabular}{ccc}
\hline Name & Unit & Value \\
\hline Drag & $\mathrm{N}$ & 0.377 \\
Lift & $\mathrm{N}$ & 0.014 \\
Cd & & 0.437
\end{tabular}

Table 6. Front wing alteration 2 data

\begin{tabular}{ccc}
\hline Name & Unit & Value \\
\hline Drag & $\mathrm{N}$ & 0.347 \\
Lift & $\mathrm{N}$ & 0.020 \\
$\mathrm{Cd}$ & & 0.402 \\
\hline
\end{tabular}


By observing the change of flow in the model as well as the results, it is clear that the change of angle of inclination does decrease the drag exerted on the car. While the lift is expected to decrease, since raising the inclination comes with an expected increase of downforce, the lift did not need to be altered compared to the data of the original design $(0.020 \mathrm{~N})$.

However, although this version of the front wing proves to be effective in lowering the drag of the car, its structure has proven to be very susceptible to damage, as seen in previous tests. The conclusions derived from this positive change will be incorporated in a more reliable version of the front wing.

\subsection{Rear Wing Changes}

Since downforce is not a necessity for F1 in Schools race cars due to the style of this race, the main wing of the rear wing is configured to zero angle of attack. The original design of the rear wing has it stem directly from the rear of the main body of the car, with the original intention of creating a rear wing without much influence on the drag or downforce. While the shape of the rear wing remains the same, vortex generators (VGs) are installed in an attempt to shrink the low-pressure area that creates drag at the rear of the car. The VGs are designed to be of the height of the boundary layer, and their shapes are of delta-wing shape (see Figure 7) or of right rectangular prism shape (see Figure 8) (Masaru, Nagayoshi, \& Hamahoto, 2004). VGs are installed on different locations of the rear of the car beside the $\mathrm{CO} 2$ container: the top, the bottom, and the sides. The reason for the testing of different shapes of VGs at different locations is to observe any potential improvement with VGs in different areas, widening the options for possible alterations.

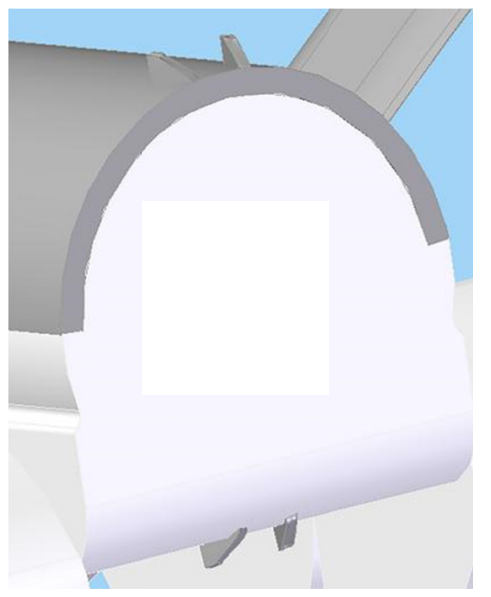

Figure 7. The delta-wing shape VGs

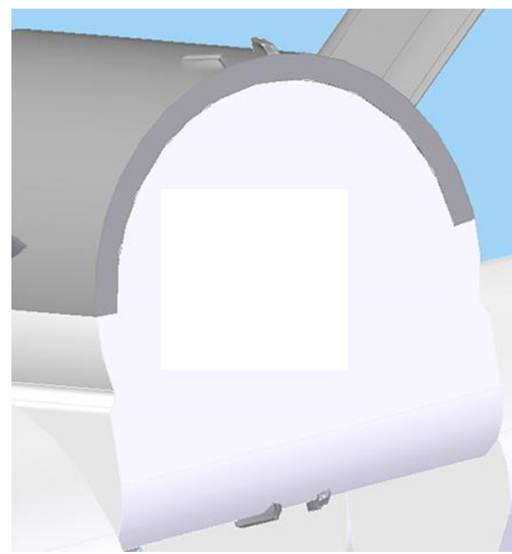

Figure 8 . The right rectangular prism shape VGs 


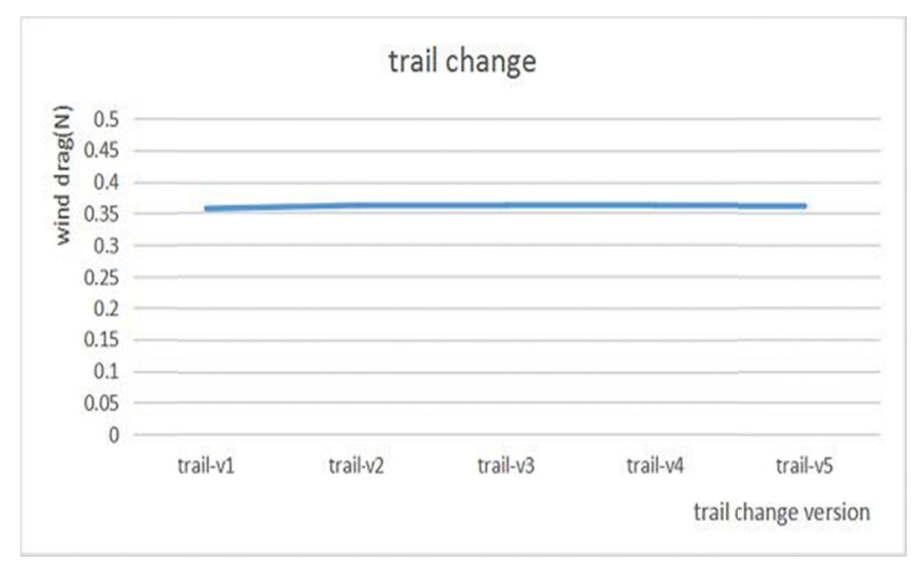

Figure 9. The change of drag force

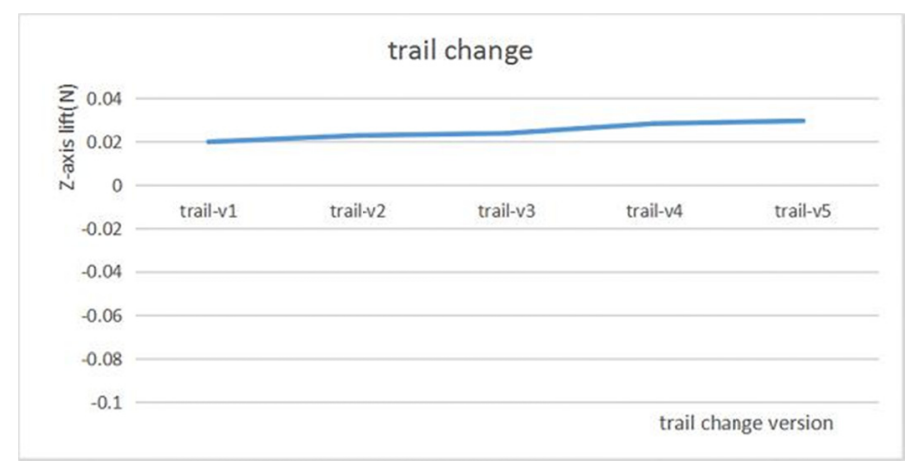

Figure 10. The change of lift

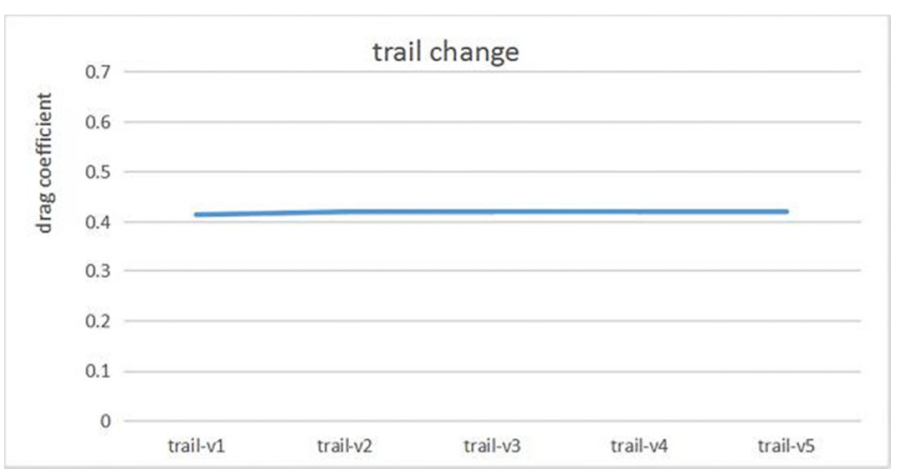

Figure 11. The change of drag coefficient

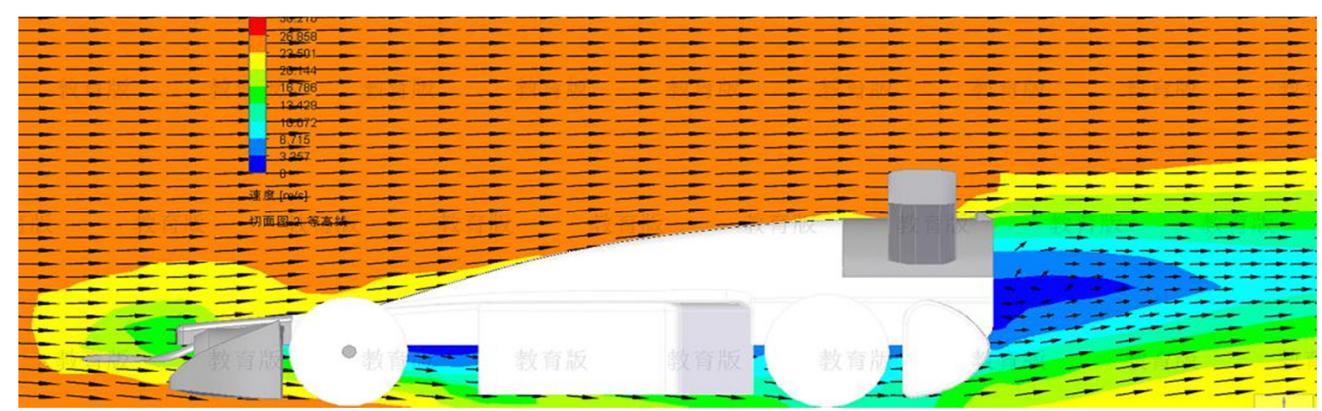

Figure 12. VG installation version 5 (velocity side view) 
The side view of the latest version of the VG installation indicates that the change to the area of vacuum behind the car is minimal (see Figure 12). The results of the tests also indicate very little improvement to the drag of the original car (see Figure 11). After analyzing the reason for the failure behind the installation of VGs, the result shows that the area of the rear of the car is large enough for the wake of the airflow to be of a certain volume that is hard to be altered by the VGs. The boundary layer separates at the sharp edge no matter what. Therefore, an effective way to reduce the vacuum area is to reduce the amount of air that can be separated by shrinking the size of the rear of the car.

\subsection{Body Change}

Several body shape changes are also made to the car in an attempt to improve its aerodynamic efficiency (Seas). Since the attempt to alter the rear of the car with vortex generators proved unsuccessfiul, the alteration of the body of the car is based upon the best version of the car from the front wing change. By observing the airflow within previous models, the sidepod is seen to attract air from the wake of the front wheels, pushing air below the car (see Figure 13).

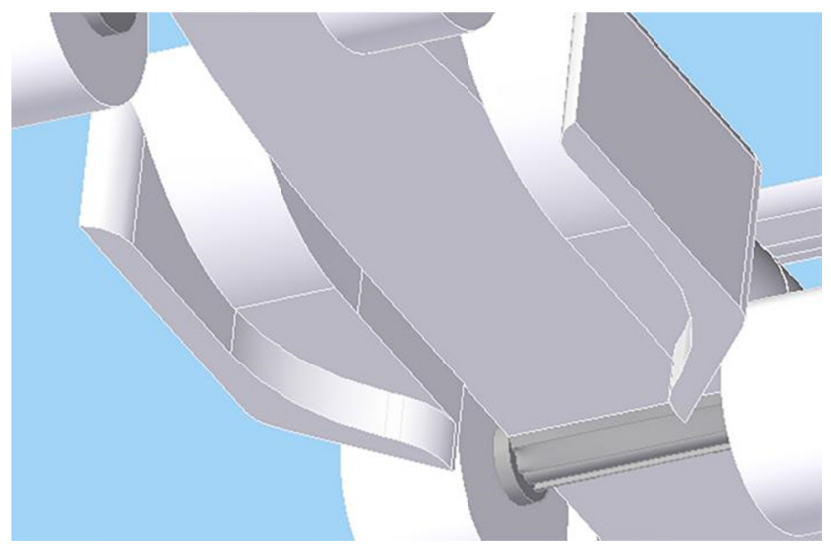

Figure 13. Original sidepod floor design

Two different reconfigurations are made to the sidepod and the floor design in an effort to improve the drag coefficient. The first is to increase the distance between the sidepod and the ground, excluding the outer skirt (see Figure 14) in order to reduce the pressure beneath the sidepod. The second is the lowering of the base of the car in order to reduce the drag with less flow separation (see Figure 15). Then, in an attempt to reduce pressure drag, the sidepod is also altered such that air is not pushed under the bottom of the car (see Figure 18).

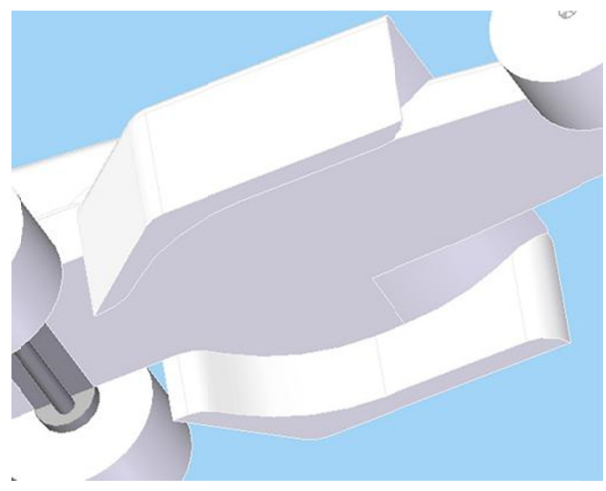

Figure 14. Raised sidepod 


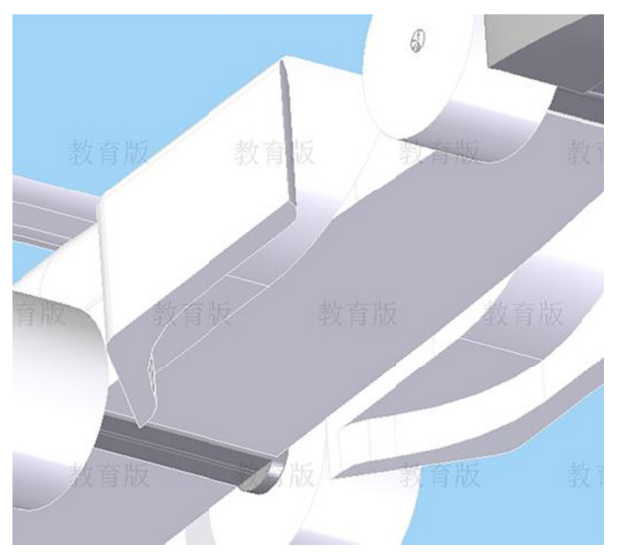

Figure 15. Lowered floor

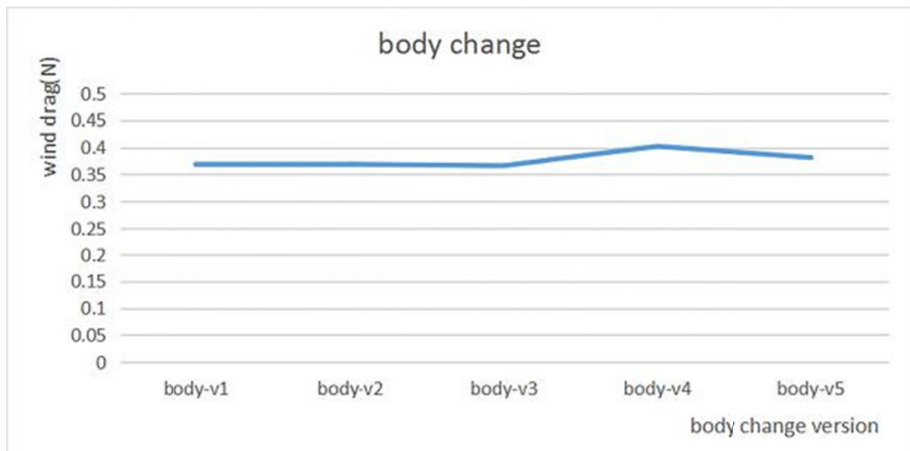

Figure 16. Change of drag force

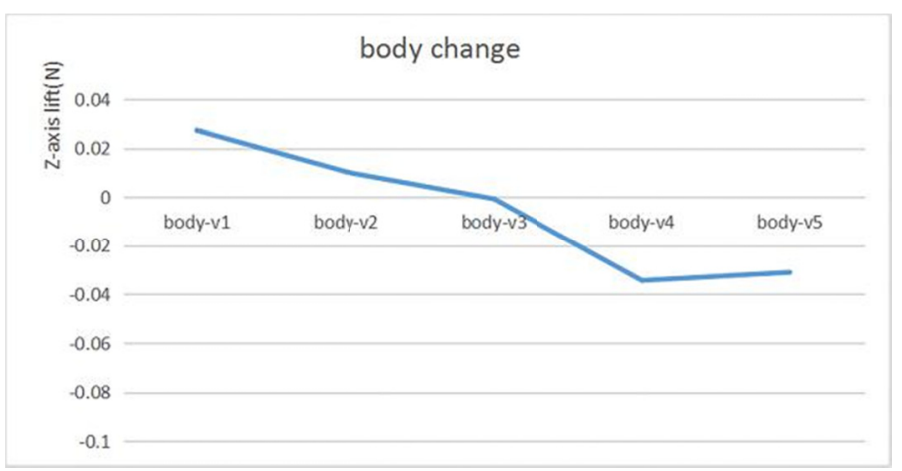

Figure 17. Change of lift

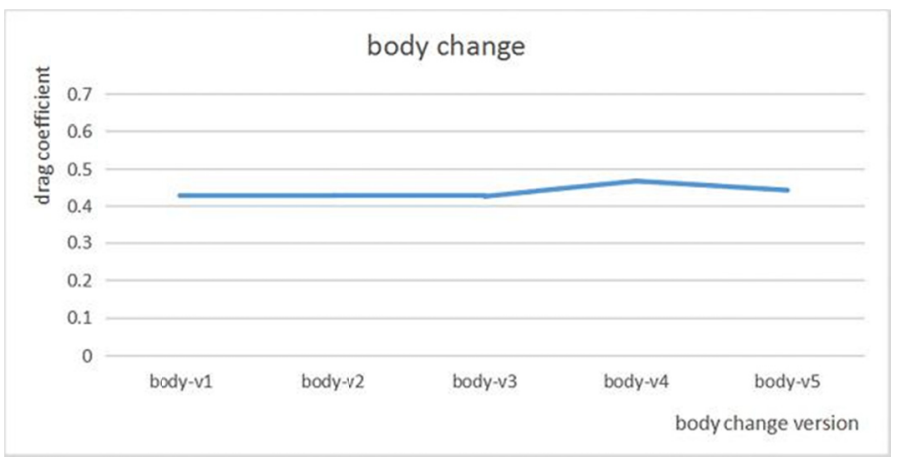

Figure 18. Change of $\mathrm{Cd}$ 


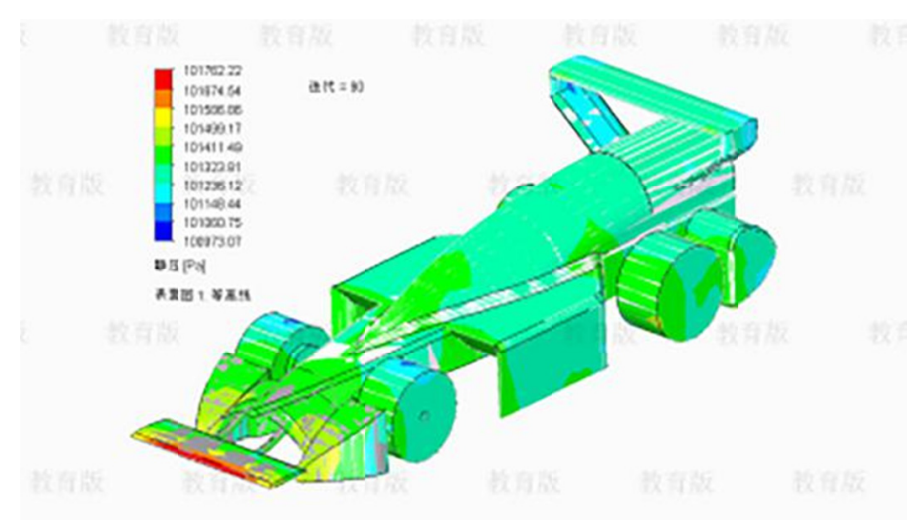

Figure 19. Body alteration 3-floor change

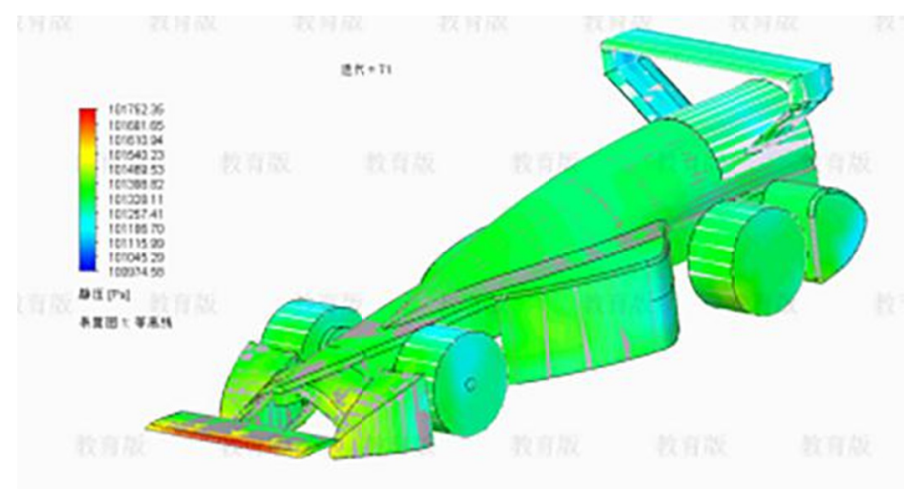

Figure 20. Body alteration 5-sidepod change

The body shape changes do not improve the aerodynamics. Any change to the bottom elevation of the car or the sidepod negatively impacts the drag coefficient of the car. The change of the sidepod shape of version four (see Figure 20) proves to be a failure as well, as the drag force and its coefficient spiked alongside a major increase in unwanted downforce. Therefore, the body shape of this version offers little in improving the drag coefficient. Therefore, a new design is created to overcome this plateau.

\subsection{Car Design Change}

After the attempted structural changes to the original race car, a new car is designed to adldress unresolved issues from past efforts. Different changes are made to the front wing, rear wing, and body shape of the car.

The rear wing's design is altered by eliminating the protrusion from the main body with the purpose of reducing observed pressure drag in the area, and the main wing is thus connected vertically from the converging body behind the rear wheels.

For the front wing of the car, the covering body in front of the front wheels does have the potential of rule violation with its height, so the height is reduced in the new design. By increasing the angle of the slope on the covering body, airflow can be directed away from making direct contact with the bluff body of the wheel. However, since the covering body for the front wheels is lowered, the airflow that would come from the main wing without an angle is predicted to make direct contact with the wheels. Therefore, several possible designs are tested with different angles of attack for the main wing, and the angle bearing the best result is deemed to be optimal. Notice the angle of the front wing in each version below (Figure 19, Figure 20, Figure 21). The first version is with the greatest angle, and the third version has the smallest. 


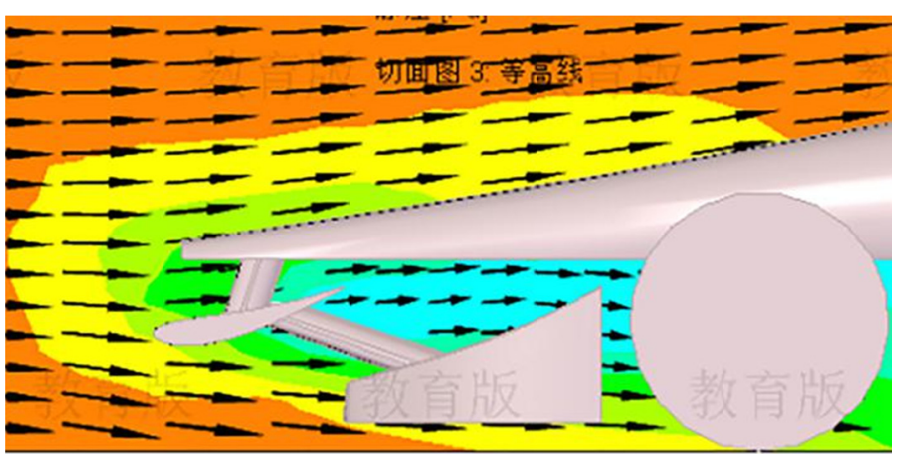

Figure 21. Angle of attack 1 (flow velocity side view)

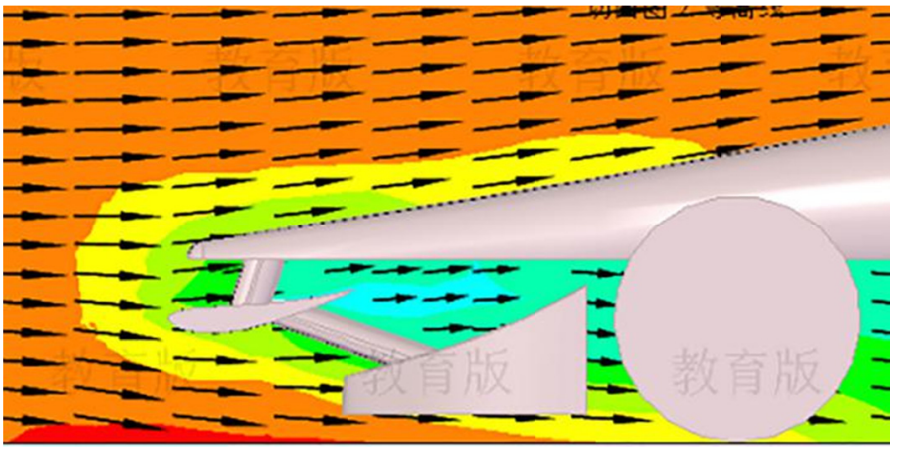

Figure 22. Angle of attack 2 (flow velocity side view)

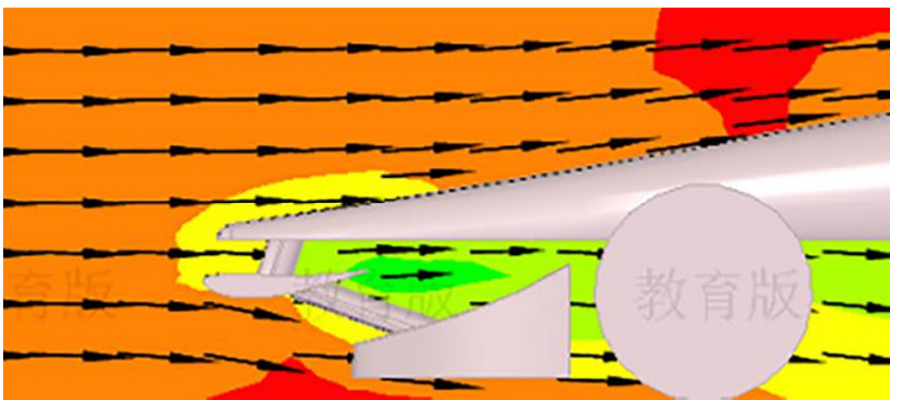

Figure 23. Angle of attack 3 (flow velocity side view)

Table 7. Comparison of results based on different angles of attack

\begin{tabular}{lllll}
\hline & & Angle of attack 1 & Angle of attack 2 & Angle of attack 3 \\
\hline Name & Unit & Value & Value & Value \\
\cline { 3 - 5 } Drag & $\mathrm{N}$ & 0.463 & 0424 & 0.324 \\
Lift & $\mathrm{N}$ & -0.090 & -0.060 & 0.028 \\
Cd & & 0.612 & 0.56 & 0.428
\end{tabular}

The third result presents the best data, with the drag coefficient already improved compared to the first model of the car.

The body shape of the car is then optimized using the best result of the angle of attack for the main wing of the front wing. To reduce the issue of low-speed air converging beneath the car in previous models, a new body shape is made to prevent such an occurrence. A much wider and taller design is made to reduce the average 
distance between the car's floor and the ground, and airflow is predicted to flow faster around a wider body, reducing the change for slow separation beneath the body, which was seen in previous models.

Additionally, the sidepod is filled to have its floor as close to the ground as the skirt is, eliminating any potential issue seen before in the body change that would occur if air went inside the sidepod (see "The Body Change"). This is also because there is a taller and deeper body next to it.

At the same time, to address the issue of lowering the separated wake region behind the car, the body is shaped to converge as much as possible within the rules at the end of the car. Since the body is shaped larger in the middle of the car, the converging bodywork is predicted to direct airflow from above and beneath the car to join as much as possible together behind the car, reducing the rear vacuum volume effectively. Notice the vacuum volume behind the vehicle in the two new designs.

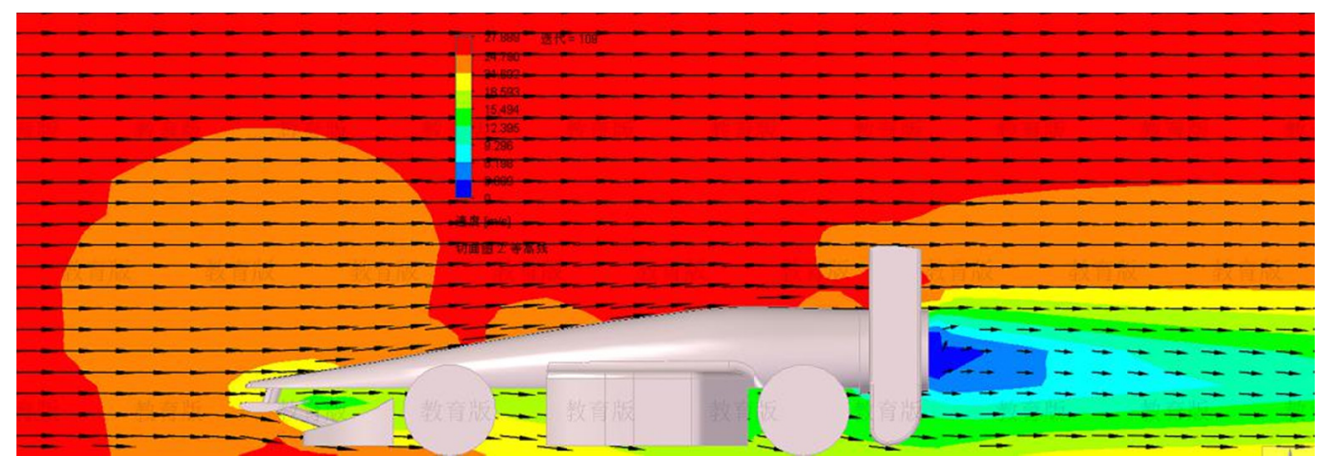

Figure 24. Angle of attack 3 (flow velocity side view)

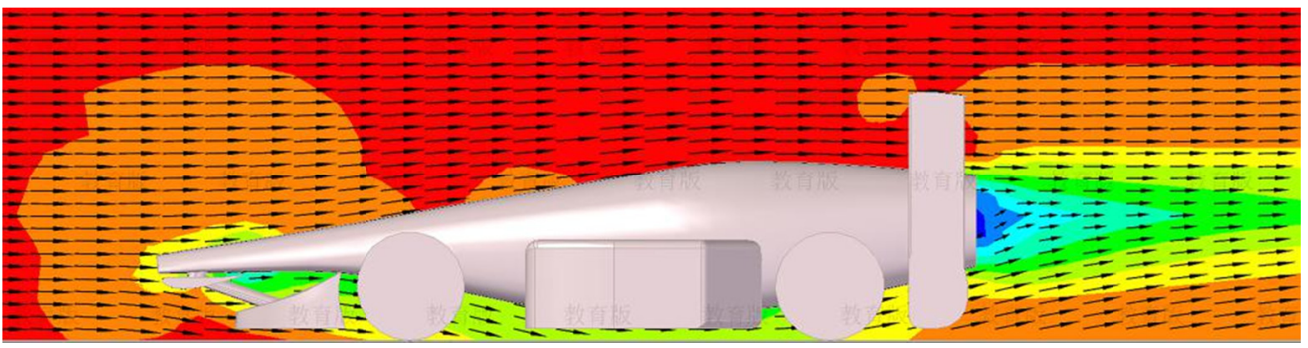

Figure 25. Body shape alteration 1 (flow velocity side view)

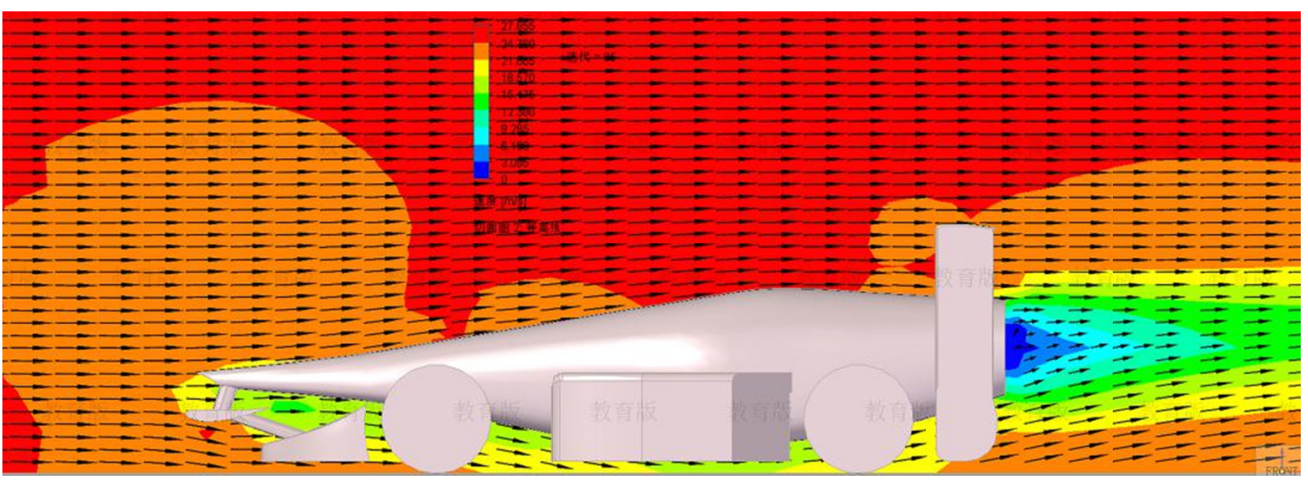

Figure 26. Body shape alteration 2 (flow velocity side view) 
Table 8. Comparison of results based on different body shapes, including the tested results of the third version of the angle of attack as well as two body shape alterations

\begin{tabular}{lllll}
\hline & & Angle of attack 3 & Body shape alteration 1 & Body shape alteration 2 \\
\hline Name & Unit & Value & Value & Value \\
\hline Drag & $\mathrm{N}$ & 0.324 & 0.335 & 0.294 \\
Lift & $\mathrm{N}$ & 0.028 & -0.069 & -0.019 \\
Cd & & 0.428 & 0.400 & 0.351
\end{tabular}

The second body shape change of the new design aims to resolve the issue of proximity between the bodywork and the main front wing that appeared to be an area of pressure drag (see Figures 23 and 24). Compared to most of the side visuals of the tested models, the final two visuals indicate a much smaller volume of vacuum air behind the car, which is likely to be the reason for the reduction in drag. At the same time, the floor of the sidepod is as close to the ground as possible, since it is not optimal for air to flow within the sidepod (which it does in the previous models) if it is open at the front and within.

\section{Conclusion}

After understanding and applying knowledge from preliminary research concerning aerodynamics, new structural designs were applied to the initial model of the F1 in Schools race car. While some did not prove to be effective, others showed major improvements.

The drag coefficient of the final version of the design, under the same circumstances that all versions of the car were tested, resulted in a drag coefficient of 0.351 , which is a 0.142 decrease from the initial value. This result indicates that the aerodynamic efficiency of the final version of the car is optimized compared to the first.

Certain major design changes proved most helpful. One was finding the optimal angle of attack for the front wing of the car. Since the front wing is the first part of the car to move through the air, it poses a great source of drag. Therefore, finding the best shape and angle for the front wing of the car is essential. Another helpful structural change was streamlining the body shape of the car. While leaving a large open space beneath the car may appear to increase drag, a larger body that converges at the rear can be more effective, as it prevents flow separation and higher-pressure air from forming beneath the car, and it reduces the separated zone behind the car.

F1 in Schools cars have straight line acceleration and straight line deceleration, and this study focuses on investigating the aerodynamic performance of the car during the steady motion phase. However, in the initial motion phase with high power, it is also important to explore the performance of the car under the influence of power. Therefore, considering the dynamic influence would be a useful direction for future research.

\section{References}

Dunbar, B. (2015). What Is Aerodynamics? NASA. Retrieved from https:/www.nasa.gov/audience/forstudents/5-8/features/nasa-knows/what-is-aerodynamics-58.html

Hall, N. (2015). The Drag Coefficient. NASA. Retrieved from https://www.grc.nasa.gov/www/k-12/airplane/dragco.html

Iljaž, J., Škerget, L., Štrakl, M., \& Marn, J. (2016). Optimization of SAE Formula Rear Wing. Strojniški vestnik Journal of Mechanical Engineering, 62(5), 263-272. https://doi.org/10.5545/sv-jme.2016.3240

John, E. S., \& Leah, R. W. (2005). Race Car Front Wing Design. Session: NSC-1: AIAA Foundation National Student Conference - Undergraduate Division. (Published Online: 21 Jun 2012) https://doi.org/10.2514/6.2005-139

Keilloh, G. (2019). Five Classic Formula 1 Ground Effect Cars. Motor Sport Magazine. Retrieved from https://www.motorsportmagazine.com/articles/single-seaters/f1/five-classic-formula-1-ground-effect-cars

Koenig, K., \& Roshko, A. (1984). An experimental study of geometrical effects on the drag and flow field of two bluff bodies separated by a gap. Journal of Fluid Mechanics, 156, 167-204. https://doi.org/10.1017/S002211208500204X 
Koike, M., Tsunehisa N., \& Naoki, H. (2004). Research on Aerodynamic Drag Reduction by Vortex Generators. Mitsubishi Motors Technical Review.

Mowbray, J. (2014). \# F1 History: Aerodynamics in Formula One - Part I. the judge 13. Retrieved from https://thejudge13.com/2014/02/05/f1-history-aerodynamics-in-formula-one-part-i/

Prager, J., Karen K., \& Denise W. C. (2020). Bernoulli's Principle - Lesson. TeachEngineering.org. University $\begin{array}{lllll}\text { of } & \text { Colorado, } & \text { September } & 2020 . & \text { Retrieved }\end{array}$ https://www.teachengineering.org/lessons/view/cub_bernoulli_lesson01

Roberts, N. (2019). Understanding Airflow - Knowing a Few Principles of How Air Flows Past a Car Can Help You Make Improvements That Really Work. NASA Speed News Magazine. Retrieved from https://nasaspeed.news/tech/aero/understanding-airflow-knowing-a-few-principles-of-how-air-flows-past-acar-can-help-you-make-improvements-that-really-work/

Seas. Ground Effect. Formula 1 Dictionary. $\quad$ Retrieved from https://www.formula1-dictionary.net/ground_effect.html

Sun, Guoliang. (2018). Racecar Front and Rear Wing Design Based on CFD. University of Qingdao, November 11, 2018. https://doi.org/10.27262/d.cnki.gqdau.2018.000192

The Columbia Electronic Encyclopedia. Photograph. Bernoulli's Law. Columbia University Press. https://doi.org/10.1002/0471743984.vse1032

Tolchinsky, I., Carrigan, T., \& Dawson, J. (2020). CAD-Based Optimization of a Race Car Front Wing. SAE Int. J. Adv. \& Curr. Prac. in Mobility, 2(3), 1422-1428. https://doi.org/10.4271/2020-01-0624

Yager, B. (2001). The Physics of Racing. NASA. NASA, August 27, 2001. Retrieved from https://www.nas.nasa.gov/About/Education/Racecar/physics.html

\section{Copyrights}

Copyright for this article is retained by the author(s), with first publication rights granted to the journal.

This is an open-access article distributed under the terms and conditions of the Creative Commons Attribution license (http://creativecommons.org/licenses/by/4.0/). 